\title{
The Use of ICT Technologies Enhances Employees' Performance in the Greek Hotel Industry
}

\section{Margarita Vogiatzi}

Department of Electronic Engineering, Technological Educational Institute of Thessaloniki, Kentriki Makedonia, Greece

\section{Email address:}

mvogia@uom.gr

\section{To cite this article:}

Margarita Vogiatzi. The Use of ICT Technologies Enhances Employees' Performance in the Greek Hotel Industry. International Journal of Economics, Finance and Management Sciences. Vol. 3, No. 1, 2015, pp. 43-56. doi: 10.11648/j.ijefm.20150301.16

\begin{abstract}
A large number of studies have been produced lately aiming to understand and explain the factors influencing the acceptance of IT by the employees of the hotel industry and create model examples, mainly based on TAM (Technology Acceptance Model) (Davis), TTF (Technology Acceptance Model) (Goodhue and Thomson) and their expansions and variations. The research effectuated mainly used empirical data from the United States, North and West Europe as well as East Asia, while a relative lack in papers is observed with regard to data coming from other touristic zones, like the Mediterranean, which, according to the EU is visited by nearly $30 \%$ Sata A. (2004) of the world tourism annually. The present paper intends to make up for that relevant insufficiency, being based on data coming from the touristic zone of Greece. Furthermore the purpose of this paper is to investigate the potential of Perceived Information Technology Beliefs, in combination with the employees' particular personal and individual characteristics, which are included in the Personal Characteristics and Subjective Norms factors, through a TAM, to affect Behavioural Intention (BI) to accept and use the Information Technologies (IT). Our findings, with the exception of the (non-significance) of Self-Efficacy, suggest that, in the Greek Tourism Sector, the harmonization of Personal Characteristics together with the other driving factors positively contributes, through a TAM, to the enhancement of Behavioural Intention; consequently, one of the first policy measures in the Sector should be the expansion of staff training in Information Technologies.
\end{abstract}

Keywords: TRA, TAM, Hotels, IT Adoption, Employees, CFA

\section{Introduction}

Within a corporate environment of heightening competition, IT can provide the impression that it might become the key to a constant competitive advantage and a potent defensive mechanism for a corporation. Buhalis D. and Deimezi O. (2003), Buhalis D., Leung D. and Law R. (2011), Buhalis D. and Kaldis K. (2008)

First, this new electronic environment, based on the Internet infrastructure, has induced a drastic cut on transaction costs for the hotel enterprises, as it eliminates possible barriers created by distance (by accumulating, processing and distributing the proper data) which were necessary for the control of the business process and, in that sense, the healthy development of the company. Chatzoglou P.D. et al. (2009), Cho V. (2006), Buhalis D and Law R. (2008), Law R., Leung L. and Buhalis D. (2009), Minghetti V. and Buhalis D. (2009), Xiaoqiu Ma J., Buhalis D. and Song H. (2003)

The advantages from the use of IT in the travel and tourism sectors have been proven by a wide number of studies, which among other things refer to the obliteration of traditional barriers, like time and geographical limitation, which are overcome by using the Internet for researching information and purchasing touristic services and products on-line. Buhalis D. and Main H.(1998), Tsai H. T. et al. (2005), Bai B. et al. (2008)

The possibility to use technologies as a driving force in order to augment the efficiency of the services provided to clients of the hotel industry will most probably become the key to succeeding in the particular sector. Maxwell G., Mcdougall M. and Blair S. (2000), Jiang J., Havitz M. E. and O'Brien R. M. (2000), Buhalis D and Law R. (2008), Law R., Leung L. and Buhalis D. (2009)

In a hotel, the use of such technologies can help save important time, thus reducing cost and at the same time permitting the transportation and distribution of information 
and as a result significantly adding to the competitive advantage of the company. Young L. H.., Woo K. G.. and Yong-Ki L. (2006), Law R., Leung L. and Buhalis D. (2009), Buhalis D., Leung D. and Law R (2011). Information Technologies (IT) constitute a fundamental element of the hotel industry as far as the productivity increase is concerned and the intensification of effectiveness, within the scope of satisfying the customers.

Internet, e-mail, electronic reservation of rooms, telecommanding meals or beverages, or other IT can influence, by significantly reducing the relevant time required for rendering services, the level of satisfaction of the visitors and the effectiveness of the particular business, resulting to the increase of competitive advantages that directly related to IT use. Verhoeven Joost W. M., Van Rompay T. and Puyn A. (2009)

Research, like the one performed by Main H. (1996), have shown that independent, medium large hotels of the United Kingdom, which constitute the larger subcategory for the industry, representing more than $60 \%$ of total rooms available, exhibit low acceptance levels, while IT use is limited and proceeds are low, in comparison to the rest of the industry. Other research like that done by Kukafka R. et al. (2003), or Henderson R. and Divett M. (2003) have set forward significant results from incorporating IT to the hotel industry, while Buhalis D. and Main H. (1998) have explained that medium large hotels in regional areas, suffering from the greatest lack in proceeds, could significantly gain from adopting or intensifying the use of IT.

Among those studying the relevant advantages of the hotel sector many have concluded that such are linked to the use of IT. Furthermore a number of studies have shown that, in order to fully gain from IT, there are certain barriers that need to be surpassed, related to the human factor, in other words the IT user. Davis D. F. (1989), Pare G. and Elam J. (1995), Roberts P. and Henderson R. (2000), Zwick T. (2002), Hu P. et al. (2003); Klein H. et al. (2006).

Such barriers standing before the successful use of information technologies are related to the point of view, the intention and the competency of the personnel using them, as well as their subsequent support by a manager. According to the above studies, IT have been designed and developed by attributing little or no attention to the requirements for, or the consequences on the employees handling them. Chau P. Y. K. (1996), Kamel N.N. and Davison R. M. (1998), Kemp S. and Dwyer L. (2001). Love P.E. et al (2005), Cho V. (2006), Chatzoglou et al. (2009).

Most studies have focused on information technology know-how and IT use in processing and services provision in relation to the bank sector, while few studies have been done in relation to the intensive tourist industry of the south east Europe. Therefore our project shall focus on the existing gap in studying the human factor, using the theory of planned human behavior as developed by Fischbein (1975) and others, as well as different theories of social knowledge found in our bibliography. Davis F. (1989); Davis F. et al. (1989); Fishbein M. and Ajzen I. (1975), Moore G. and Benbasat I. (1991),
Thompson R. et al. (1994), Davidson E. (2002), Roberts P. and Henderson R. (2000)

The purpose of this study is to conduct research on the relationship existing between conviction, self-efficacy and subjectivity with the behavior and the intention towards adopting information technologies by hotel employees. More particularly, our study shall focus on the following subjects:

1. Study how the diffused perception over information technologies may guide the convictions that steer the creation of an opinion with regard to the adoption of such technologies.

2. Examine the impact of the adjustment of the professional know-how of the employees in relation to their stance towards adopting information technologies.

3. Evaluate the impact of their personal (self) satisfaction in their behavior.

4. Check in what way the behavior, personal satisfaction and the personal social type of ranking the individual may form a certain behavior, thus creating a particular intention, towards the adoption of information technologies.

Our goal is to help develop a theoretical approach regarding the contribution of information technologies on the hospitality industry and suggest a practical tool for the adoption of IT by the personnel of the industry.

\section{Bibliography Overview}

\subsection{Theory of Reasoned Action (TRA)}

Older studies, in order to interpret the use of Information Systems (IS), were based on theories and models of behavioral decision. Ajzen I. and Madden T. (1986), Mathieson K. (1991). In particular the issues of the acceptance and adoption of IT use by the employees of the hotel industry, particularly those occupied in working positions relevant to technology, have been intensively researched in the past. Fishbein M. and Ajzen I. (1975), Ajzen I. and Madden T. (1986), Adams A. et al. (1992) have developed TRA, by introducing important (determining) factors that they have "borrowed" from the sciences studying human behavior, namely psychology and sociology. Their results have proven the existence of a statistically important positive correlation with actual behavior. The results of such searches prove that a positive intention with regard to the adoption of Information Systems is fundamental to their effective use.

In particular, social sciences have developed the theory of reasoned action (TRA). Ajzen I. and Madden T. (1986), Mathieson K. (1991), Agarwal R. and Prasad J (1997), Agarwal R. and Prasad J (1999). According to them, in behavioral terms, an individual's propensity to perform an act in relation to a particular objective stimulation resulting within a determined situation depends on the person's attitude towards the behavior and the subjective norm (SN). Subjective norm means the canonical convictions of an individual, based on two factors weighed by multiplication. In other words individuals tend to act more when they believe 
that the pressure they are subjected to, in order to perform such action, originates from the highest social classes. Ajzen I. (1991), Pavlou P. and Chai L. (2002), Pavlou P. and Fygenson M. (2006),

That is what hotel managers stand for, while the positive opinion of managers over the corporate advantages resulting from the adoption of Information Technologies have led to an indirect pressure to their employees so as for them to use such technologies. Davis F. et al. (1989), Ansel D. and Dyer C. (1999), Enz A.C. and Siguaw A.J. (2000), Enz A. C (2001), Anandarajan M., Igbaria M. and Anakwe U. (2002) ,Watson Sandra (2008).

\subsection{Basic Technology Acceptance Model (TAM) or Extended Task-Technology Fit (TTF) Variation}

Within TRA, Davis F. (1989) has suggested the measurement of IT adoption, the TAM model, in other words the Technology Acceptance Model. There, he included the data and the determining factors of the theory: the attitude and the behavioral intention. The functionality of the model is reinforced by two fundamental factors, the perceived ease-of-use and the perceived usefulness. The potent projection capacity, the ease of use and particular IT usefulness have been the object of a great number of studies, like those of Davis F. et al. (1989), Agarwal R. and Prasad J. (1997), Agarwal R. and Prasad J. (1999), Venkatesh V. and Davis F. (2000), Moon W.and Kim G. (2001), Anandarajan M. Igbaria M. and Anakwe U. (2002), Saade R. and Bouchaib B. (2005), Cho V. (2006) and others.

It is generally accepted as true, that the assumption of the Technology Acceptance Model (TAM) make it somehow more restrictive in comparison to the TRA notion, for instance the Information Technology adoption is mandatory and does not include the factor of Subjective Norm (SN) (Taylor S. and Todd P. (1995) Venkatesh V. et. al., (2003), Young L. H., Kim G. W. and Yong-Ki L. (2006), Hu H., Kim T. and Law R. (2009)), while TRA deems that the choice of the employee to use IT or not as optional.

Goodhue D. and Thomson R. (1995) have proposed a variation-extension of the model, by suggesting Task-Technology-Fit (TTF) basing its function to the addition of another determining factor for the IT adoption called TTF, which strongly depends from whether IT technology is reliable, appropriate and compatible for the task or mission at hand. Dishaw M. and Strong D. (1999), Goodhue D. Klein B. and March S. (2000), Cho V. (2006), Lin T. C. and Chuang C. C. (2008)

They have suggested that IT, in conjunction with other inputs, constitute a tool for the employees in order for them to improve effectiveness within the particular mission -output.

Taylor S. and Todd P. (1995) remarked that the sample used by Davis, drawn from University students, may provide an explanation with regard to the non importance of the Subjective Norm (SN) that contradicts the personal professional image that an employee of the financial services industry projects.

In order to better understand IT use, they introduce the notion or prior experience to IT use or not, suggesting a TAM variation. In such, the ease-of-use and the high usefulness of IT affect the perception together with $\mathrm{SN}$ and the Perceived Behavioral Control (PBC), while they affect the Behavioral Intention (BI) which finally leads to the manifestation of the particular behavior.

According to Dishaw M. and Strong D. (1999), TAM looks different than TRA. At first, it specifies the notion of ease-of-use and of high IT usefulness, as being external factors or determining beliefs with regard to the attitude towards IT. Secondly, TRA does not include SN which is not considered important, while it is precisely $\mathrm{SN}$, along with the perception, that measure the behavioral intention according to TRA. They propose, as a consummate model for measuring IT acceptance, a coalescence of the TAM and TTF models.

$\mathrm{Hu}$ P. et al (1999), work on technology adoption on the medical field, using a simplified TAM version with three determining factors, where the perceived ease-of-use affects the perceived usefulness and the perception, while the perceived ease-of-use influences the perception and the Behavioral Intention (BI) for technology use and finally the attitude determines in turn the propensity to use technology. They propose the use of a specific hypothesis according to which the degree to which the ease-of-use of telemedicine by doctors affects both the perception of the high usefulness of the particular technology as well as the general attitude towards IT technologies.

In the last decade a number of researchers such as Goodhue D. et al. (2000), Heine L. et al. (2003), Hu P., Clark T. and Ma W. (2003), Sun H and Zhang P. (2006), Lam T. et al. (2007) among others, wanting to increase the explanatory potency of the two main models: TAM and TTF, have examined the possibilities to develop them, through differentiations, extensions or incorporations of their own suggestions to the two models.

\subsection{The Employee Personal Characteristics}

Many writers, among which Igbaria M. (1990), Guimaraes T., Yoon Y. and Clevenson A.(1996), Cho V.(2006), Bai B. Low R. and Wen I.(2008) and Lee H. and Lee Y. (2006), deem it necessary to take account of the personal or demographic characteristics of the employees, such as sex, age, time of employment and position in the company's hierarchy. We follow Lee H. and Lee Y. (2006) taking account of sex, age and education.

H1: A more positive Personal Characteristics cause higher Perception about IT.

\subsection{The Perceived Self-Efficacy}

Bandura A. (1982) has concisely described the notion of the perceived self-efficacy as the person's assessment of their ability to organize capabilities of concrete know-how, within the society and in relation to the behavior they already demonstrate, so that by mastering them they may fulfill the requirements presenting themselves at a possible situation.

Perceived self-efficacy constitutes one of the elements that 
form an individual's decision to accept and use IS at his or her work. Bandura A., Adams N. and Beyer J.(1977); Bandura A., et al.(1980); Bandura A.(1982); Igbaria M.. and Ivari J. (1995) Hayashi A., et al (2001), Venkatesh V., et al, (2003) Hong W., et al (2002),Hu P. et al (2003), have significantly contributed, among others, to the emergence of the notion of self-efficacy. The particular importance of the perceived self-efficacy is established by the fact that individuals who have experienced a loss in their faith to their competencies in using IS are disappointed and cannot achieve their objective, while those who strongly believe in their competencies intensify their efforts until the achievement of their objective.

Perceived self-efficacy plays a more important role to the completion of relevant simple tasks while it is of medium importance when the complexity of the necessary action is increased. Conger J. and Kanungo R. (1988), Gist M. and Mitchell T. (1992), Marakas G., Yi M. and Johnson R. (1998), Venkatesh V., et al (2003) Pavlou P. and Fygenson M. (2006), and others.

In any case and independently to the degree of its contribution, Stajkovic A. and Luthans F. (1998) the perceived self-efficacy is presented, in various studies, as positive and statistically important in relation to the individual's competence, being refueled and reinforced by it, hence the hypothesis:

H2: The higher the Self-Efficacy level, the more positive the Perceived IT Beliefs towards IT acceptance.

Perceived self-efficacy, as a tool, has been adopted by Igbaria M. and Ivari J. (1995) as well as $\mathrm{Hu}$ et al. (2003) transcribed in three questions which examine the competence in the use of IT of particular individuals with regard to each specific task, in compliance with the Likert scale from 1 to 5.

\subsection{The Perceived IT Beliefs}

Research done on Management Information Systems (MIS) (notably Moore G. and Benbasat I. (1991); Davis F. (1993); Agarwahl R. and Prasad J. (1997); Corsun D.and Enz C. (1999); Agarwahl R. and Karahanna E. (2000); Bhattacherjee A. (2001); Agarwal R., Sambamurthy V. and Stair R. (2000), among others) it became clear that the attitude of the individuals-employees towards adopting innovative technology is determined by their perceived beliefs, the qualities-advantages that such act may include or incorporate and in particular by its ease-of-use, its special usefulness, its compatibility, the image it creates for the user of such technology and the possibility to experiment with it on trial basis.

From the perceived beliefs we discover that the positive opinion of a user with regard to the application of a new technology may further enhance employee effectiveness along with the awarding increases in pay, bonuses and other rewards Furthermore a potent opinion may further enforce employees even more towards the achievement of high performances Davis F. et al. (1989), Davis F. (1993).

Davis F. (1989) has established the existence of a positive correlation between the opinion of the employees over the ease-for-use of a new technology and the determining attitude towards the application of the particular technology. Rogers E.M. (1983), has recognized five characteristic qualities that determine the acceptance and diffusion of innovation, those are: relative advantage, compatibility, complexity, trialability and observability.

He defined compatibility as the degree to which an innovation may be perceived as consistent with the existing values, past experiences and needs of its potential adopters, while complexity is the degree to which an innovation is perceived as relatively difficult to understand and use. Rogers E.M (1983), Moore G. and Benbasat I. (1991), Adams D. et al. (1992), Ramiller N. (1994); Wixom B. and Todd P. (2005).

Trialibility is the degree to which an innovation may be experimented without risk while it encourages, according to the findings of Davis F. (1989), Moore and Benbasat (1991), the positive effect on the disposition or potential adopters towards it. A new technology which also provides the possibility of trial application, in the initial stages without risks, removes an important barrier facilitating its acceptance by potential adopters.

By allowing experimentation on a trial basis, at an initial stage, without posing any risks, a new technology may eliminate an important barrier that would otherwise stop its acceptance by potential adopters.

Agarwal R. and Prasad J. (1997) have explained that the more the potential adopters of a new technology are convinced that they may experiment with it, on a trial basis, at the initial stages of its application, the greater are the chances of it being finally adopted. This is how the hypothesis is structured, according to our bibliography.

The Perceived Usefulness of ITs, as defined by Davis F., Bagozzi R. and Washaw P. (1989) and the Perceived Ease of Use, introduced by Davis (1989) and Venkatesh V. and Davis F. (2000), constitute determinants for the strengthening of IT use by people. Lam T. et al.(2007), Hung S. Y. and Chang C. M. (2005), Huang E. and Chuang M. H. (2007), Huh H., Kim T. and Law R. (2009). Lam T. et al.(2007) considers these two factors as incorporated in another factor, which he acknowledges as Perceived IT Beliefs, which brings about the exact results with the two factors above and may, thus, replace them.

H3. More positive beliefs for the IT technologies enhance the positive Attitude towards IT adoption.

Beliefs regarding IS as a tool have been adopted by an older study performed by Moore G. and Benbasat I. (1991) and have been extensively used by us for our present research, in order to include the employee beliefs on IT use in hotels, in general. The questions of the questionnaire are distributed in compliance to the Likert scale, starting from 5"totally agree" to 1 "totally disagree".

\subsection{The Task-Technology-Fit}

Goodhue D. and Thomson R. (1995) after mentioning prior studies which had already indicated the particular important of task-technology-fit and the willingness of an employee to perform his tasks by using IT, have defined it as the preparedness of someone to use IT in his work in order to 
increase productivity, to the point that the technology helps someone apply his portfolio of tasks.

Cho V. (2006) concludes that the compatibility of new technology or Task-Technology Fit are factors affecting Attitude (ATT) Intention and Behavior in the adoption of new techniques.

The result of their study point out that TTF role in using IT, becomes eminent through the connection between being task technology fit and the beliefs regarding the consequences (results) of a system use.

Dishaw M. and Strong D. (1999), have expanded TAM with a TTF (task technology fit) construction. Their research has showed that the expanded model TAM/TTF represented a better explanation with regard to the fluctuations present on IT use, as resulting from the use of TAM and TTF models alone. The united TAM/TTF model combines the TAM model for behavioral attributes with the task technology fit model (TTF). In the united model presented by Dishaw M. and Strong, D. (1999) the TTF infrastructure is directly influencing IT use, while it also reacts indirectly to it through original explanatory variables of the TAM on perceived usefulness and perceived ease of use.

The importance of being task technology fit is underlined by a great number of studies, namely Huh H. et al. (2009), Huang E. and Chuang M. (2007) and Heine L. et al. (2005) who all end up to the conclusion that the task technology fit quality and IT use intensify the acceptance effort of IT originally by the employees.

Morris M. and Turner J. (2001) explain that the compatibility of IT to serve in the execution of a specific task is related to its essence, according to social sciences, to the personal or subjective opinion that the user of the particular technology forms for it. In other words, the stronger the opinion the stronger the TTF, thus the hypothesis:

H4: The more positive the TTF the stronger the Attitude about IT.

We have borrowed the structure used by Goodhue D. and Thomson R. (1995), while we have adapted the originally five questions into three, in order to better correspond to the needs of our sample on the basis of the 5 point Likert scale.

\subsection{The Attitude}

The attitude an individual maintains towards IT use has been examined during the past decades by a great number of studies, either as an independent factor, or incorporated into composite hypothesis structures, with varied evaluations of its importance.

In the past the attitude of employees towards innovation and in particular the adoption and use of IS in the hospitality industry, was widely researched, aiming to enhance the effectiveness of human resources and reinforce corporate performance in general.

The importance of a voluntary positive attitude of employees regarding the acceptance of IS system use is obvious, in comparison to a situation where employees use IS systems because they have to, while they personally feel negative towards them. Therefore we consider that researching the attitude of the individuals towards the adoption and implementation of IS systems in a company is of great significance.

V. Cho (2006) accepts the suggestion by Fishbein and Ajzen (1975) that a person's beliefs anticipate their attitude, and their conclusion that this attitude depends on behavioural beliefs and outcome evaluation.

Andarayan et al. (2002) also confirms the position of Fishbein and Madden (1985), according to which the research on the attitude of an individual was based on the TRA tool. The attitude towards a behavior is an individual's positive or negative perception of psychological or sentimental nature towards an object, a person, an institution, a system or a situation.

The attitude an individual maintains towards IT use has been examined during the past decades by a great number of studies, either as an independent factor, or incorporated into composite hypothesis structures, with varied evaluations of its importance.

Karahanna et al. (1999), in particular, have presented arguments supporting their opinion that attitude influences behavioural intention; also, Cho V. (2006) has argued that TRA (Theory of Reasoned Action) is a well-accepted model for explaining the attitude - intention - behaviour relationship, formulating the following hypothesis:

H5: The more positive the attitude the more powerful the behavioral intention.

The attitude tool is based on the work of Mathieson K. (1991), Ham S., Kim W. and Forthsythe H. (2008) slightly modified in order to emphasize the interest and the significance of IT for the employees, while there is an additional question, in order for the tool to be complete in four total questions, in compliance with the Likert scale. 


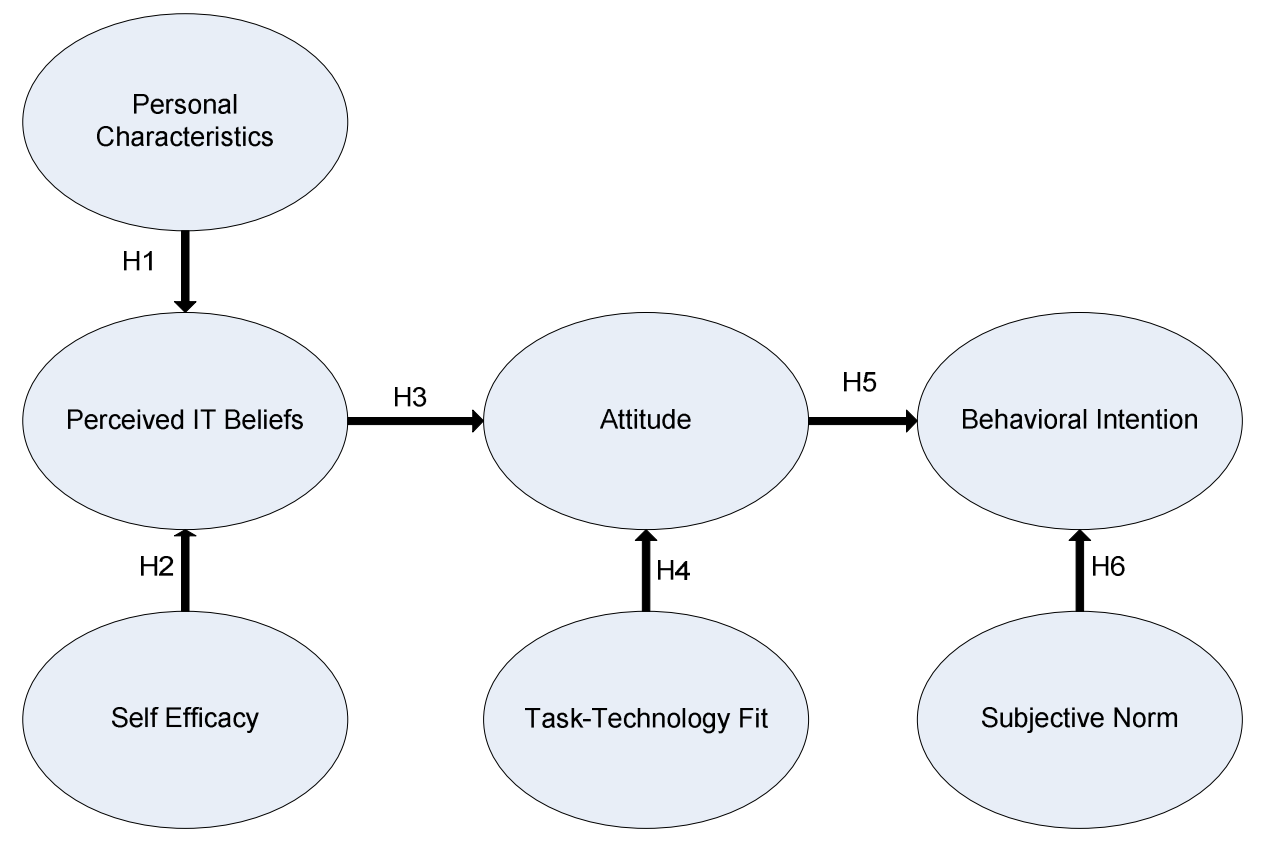

Figure 1. Researched Model

\subsection{The Subjective Norm (SN)}

Among the factors of every organizational construct Ajzen I. and Madden T. (1986); Davis F. et al. (1989), Gist M. and Mitchell T. (1992); Subjective Norm (SN) is of key importance, according to Igbaria M., Ivari J. and Maragahh H. (1995); Taylor S. and Todd P. (1995). Each individual pertains to a particular one according to the group of particular characteristics emanating from his or her behavior and which at the same time determine it.

Ajzen I. and Madden T. (1986) believe that the Subjective Norm expresses the social pressure that is placed on the individual to perform the specific behavior. Also a great number of studies like those of Davis F. et al. (1989); Buttle F. and Bok B. (1996); Bowen J. (1997); Hutching K., Lac A. and LaBrie J. (2008) and others, maintain that the beliefs of an individual are positively and in a statistically important way related to the Subjective Norm.

Ajzen I. and Madden T. (1986) have accepted that the individuals, in compliance to their particular Subjective Norm, respond to normal expectations of others belonging to their immediate social background following a precise hierarchical pattern; more particularly they respond first to their superiors, then their parents, their spouse, boyfriend or girlfriend, their children or guardian, their friends or peers, or schoolmates and finally the rest of society. Pressure to particular individuals to accept a system or not, results, all the more when we speak of IS acceptance, to them feeling that others expect them to accept a system, thus develop in a greater degree the intention to adopt it even if personally they are not comfortable with it.

The Subjective Norm Ajzen I. (1991), refers to the social pressure to which an individual is subjected in order to behave (or not) in a specific way. Thus the hypothesis:

H6: A higher level of Subjective Norm shall cause a stronger intention to accept IT.

We have borrowed the notion from Karahanna E., Straub D. and Chervany N. (1999) and Mathieson K. (1991) and adjusted it to four questions distributed according to the same Likert scale.

Table 1. The Factors and his items used in this work.

\begin{tabular}{|c|c|}
\hline $\begin{array}{l}\text { Factors } \\
\text { Items }\end{array}$ & $\begin{array}{l}\text { Variance explained from CFA } \\
\text { (Standardized coefficients from SEM }\end{array}$ \\
\hline Perceived IT Beliefs, (Cronbach's Alpha: 0.8053) & $60.502 \%$ \\
\hline - Perceived usefulness: Adopting IT in my job enables me to accomplish tasks more quickly & {$[0.41]$} \\
\hline - Perceived ease of use: I found it easy to use in hotels & {$[0.40]$} \\
\hline - Perceived compatibility: Adopting IT is a new experience for me & {$[0.42]$} \\
\hline - Perceived image: : People who adopt IT have more prestige than those who do not & {$[0.44]$} \\
\hline - Perceived trialability: : Before deciding to use IT, I would be able to properly try it out & {$[0.43]$} \\
\hline - IT dependence The information system is available when needed & {$[0.59]$} \\
\hline - Information dependence: The data is displayed in a readable and understandable form when needed & {$[0.60]$} \\
\hline - Decision making dependence: The information system can enable me to make good decision & {$[0.60]$} \\
\hline Self-Efficacy, (Cronbach's Alpha: 0.8239) & $71.452 \%$ \\
\hline - Workability: : I will understand the working principle of a new information system & {$[0.59]$} \\
\hline - Applicability: I will be able to learn the application of a new information system & {$[0.58]$} \\
\hline -Variability: The information system varies a lot and it is not easy to operate & {$[0.50]$} \\
\hline
\end{tabular}




\begin{tabular}{ll}
\hline $\begin{array}{l}\text { Factors } \\
\text { Items }\end{array}$ & $\begin{array}{l}\text { Variance explained from CFA } \\
\text { (Standardized coefficients from SEM }\end{array}$ \\
\hline Attitude, (Cronbach's Alpha: 0.8526) & $63.567 \%$ \\
- IT is important to my job & {$[0.56]$} \\
- IT is relevant to my job & {$[0.59]$} \\
- IT is trifle & {$[0.60]$} \\
- IT is interesting & {$[0.58]$} \\
- IT is attractive & {$[0.51]$} \\
Subjective Norm, (Cronbach's Alpha: 0.8155) & $69.271 \%$ \\
- My supervisor always encourages me to use information systems & {$[0.65]$} \\
- My colleagues think that I should use information systems & {$[0.63]$} \\
- My guests perceive using information systems to be useful in a hotel & {$[0.60]$} \\
- My hotel manager believes that there are advantages of using & {$[0.58]$} \\
information & $74.271 \%$ \\
Behavioral Intention, (Cronbach's Alpha: 0.8213$)$ & {$[0.64]$} \\
- I intent to work with IT more increasingly in the future & {$[0.63]$} \\
- I want to use IT for my work & {$[0.59]$} \\
- It is likely that I will use IT for my future work & {$[0.53]$} \\
Personal characteristics & {$[0.70]$} \\
- Gender (' 1' = male, '2' = female) & {$[0.51]$} \\
- Age (' 1' = up to 30 years, '2' = more than 30 years) & - Education (' 1' = high school \& lyceum, '2' = college \& university) \\
\hline
\end{tabular}

*Source: Adapted from Lam, Cho and Qu (2007).

\section{The Research Model}

Specifically, resting upon Lam T. et al. (2007), we present a business model according to which the independent factors Self-Efficacy (SEF) and Personal Characteristics significantly affect the Perceived IT Beliefs (PIB). Attitude is affected by Perceived IT Beliefs and Task-Technology Fit. Finally, in the following phase Attitude and Subjective Norm affect the adoption of new technology by the employees.

The objective, thereby, of the paper is to explore how Self-Efficacy (SEF,) and Personal Characteristics (PC) have an effect on Perceived IT Beliefs (PIB), which then, and jointly with Task-Technology Fit (TTF), affects Attitude (ATT) and the latter, with Subjective Norm (SN), affect Behavioral Intention(BIN).

In TAM samples by Lam T. et al. (2007) and Taylor S. and Todd P. (1995) Behavioral Intention (with respect to IT acceptance in hotels) is positively affected by strengthening the Attitude which was previously positively affected by perceived usefulness and perceived ease of use, while Lam T. et al. (2007) proposed we replace the Perceived Usefulness and Perceived Ease of Use by the concept-variable Perceived IT Beliefs.

The assessment of the impact of Perceived IT Beliefs and Attitude as forecasting factors for Behavioral Intention and of the relations to Self-Efficacy and Task-technology fit and complementary to Subjective Norm, was conducted by the application of a Structural Equation Model (SEM), the Confirmatory Factor Analysis (CFA) and the Maximum Likelihood Estimation (MLE) method.

Admissible loadings for the components were considered to be those greater than $50.00 \%$. The construct internal consistency was tested by the calculation of Cronbach's alpha coefficient. Cronbach's alpha reliability coefficients ranged from 0.723 to 0.905 which exceeds Nunally C. and Bernstein's (1994) admissible levels of 0.70 . The total variance percentage may be explained by the change of the variables which exceeds by large $50 \%$ suggesting that the measurement-registration tool. Survey Instrument, is admissible.

\subsection{Sampling Methodology}

We have concluded an empirical survey through the use of questionnaires distributed to employees who, because of the nature of their work, had to use a computer in hotels located in four different touristic zones of Greece. The employees who took part in the research study were informed before and during the study: 1) of the reasons for carrying out the study; 2) of the study's goal; and 3) of the positive results expected from the study, both for the staff and for the business. As for the individuals who accepted to answer, we made sure that the questionnaires were completed within a few hours, because as research has shown in the past, direct answers tend to be the most accurate. Questionnaires were distributed in the hotels, to employees whose specific duties required them to be in direct contact with the hotel's guests in the restaurants, i.e. waiters, chefs and restaurant and bar managers, staff members providing sports or other recreational activities and spectacles, performers, as well as employees at the hotel's reception departments. First we questioned 1023 people and we gathered 217 completed questionnaires or $21,22 \%$.

The research/inventory tool, Survey Instrument, regarded the development of a questionnaire which served for taking it

The research was conducted from January to July, 2009 (in 17 hotel units. After coming to contact and consulting with hotel executives, 1023 self-administrative questionnaires were send; these were handed out to the interviewees by hotel personnel managers or human resources executives, in 3, 4 and 5 star hotels, in the seaside resorts of Halkidiki, near Thessaloniki, in the area of Volos and Mt. Pelion, in Patra and Athens.

217 of these questionnaires were returned filled, $21.22 \%$ of 
those send out. $54.21 \%$ of the respondents were women and $46.79 \%$ were men. The majority of the responses, $71.34 \%$, were by people who were with the company for less than 3 years, while $28.65 \%$ had worked for the hotel for a longer period. $52.43 \%$ were middle-school graduates, $27.56 \%$ high-school graduates and $20.00 \%$ had graduated from technical and vocational training institutions. 58.31\% were up to 34 years old and $41.69 \%$ older than 35 .

\subsection{Statistical Process}

Aiming to reduce the number of variables and group them in categories, we implemented a principal component analysis and varimax orthogonal rotation and an Eigenvalue greater than one.

It is noted at this point that for the carrying out of Structural Equation Model (SEM) factor analysis Confirmatory Factor Analysis (CFA) was preferred over Exploratory Factor Analysis (EFA), due to the advantages exhibited by the first, since it tests a priori known hypothesis and overcomes the problem of the non-unique solution which burdens the EFA, Bagozi R. and Yi Y. (1988).

Table 2 shows the arithmetic means, standard deviations and correlation coefficients, between all pairs of variables used in this work.

The values appearing in Table 1 of the sample and are higher than 0.70 Nunnally C. (1978) suggest the instrument is reliable for testing the sample. Construct validity was tested for the percentage of variance for each item with respect to total variance, which appears in Table 2 of the application of the validating principal components analysis with a varimax rotation and an Eigenvalue greater than one. The individual avariances exceed $50 \%$ and are admissible. CFA is preferred over EFA, due to the fact that its advantages prevail, while it is applied to a known theory for testing a priori hypotheses with specific questionnaires which have been used before and are of tested reliability.

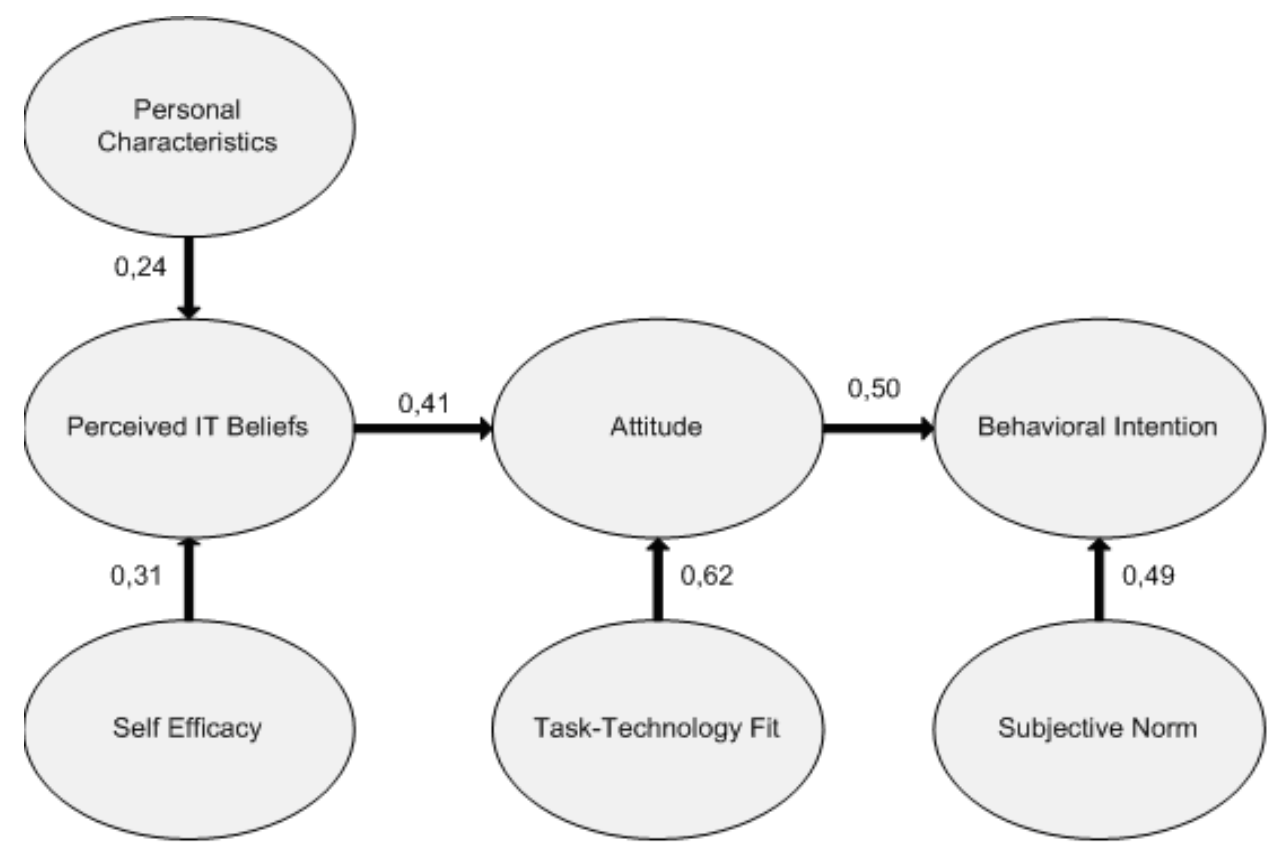

Figure 2. Standardized Estimates of Researched Model

Table 2. Means, standard deviations, and correlation coefficients of all variables included in the study

\begin{tabular}{|c|c|c|c|c|c|c|c|c|c|c|c|c|}
\hline & \multirow[b]{2}{*}{ Mean } & \multirow{2}{*}{$\begin{array}{l}\text { Standard } \\
\text { Deviation }\end{array}$} & \multicolumn{10}{|c|}{ Correlati Correlation coefficients } \\
\hline & & & $\begin{array}{l}\text { Perceived } \\
\text { Beliefs }\end{array}$ & $\begin{array}{l}\text { Task- } \\
\text { technology fit }\end{array}$ & Self-Efficacy & Attitude & $\begin{array}{l}\text { Subjective } \\
\text { Norm } \\
\end{array}$ & $\begin{array}{l}\text { Behavioral } \\
\text { Intention }\end{array}$ & Gender & Age & Education & Position \\
\hline $\begin{array}{l}\text { Perceived IT } \\
\text { Beliefs }\end{array}$ & 4.0821 & 0.78143 & 1 & & & & & & & & & \\
\hline $\begin{array}{l}\text { Task-technology } \\
\text { Fit }\end{array}$ & 4.2751 & 0.71217 & 0.412 & 1 & & & & & & & & \\
\hline Self- Efficacy & 4.8112 & 0.76112 & -0.407 & 0.487 & 1 & & & & & & & \\
\hline $\begin{array}{l}\text { Subjective } \\
\text { Norm }\end{array}$ & 4.1487 & 0.75041 & 0.496 & 0.410 & 0.469 & 0.511 & 1 & & & & & \\
\hline $\begin{array}{l}\text { Behavioral } \\
\text { Intention }\end{array}$ & 4.2765 & 0.61247 & 0.411 & 0.566 & 0.571 & 0.744 & 0.504 & 1 & & & & \\
\hline Gender & & & 0.289 & 0.414 & 0.378 & 0.586 & 0.404 & 0.809 & 1 & & & \\
\hline Age & & & -0.339 & -0.310 & -0.723 & -0.434 & -0.399 & -0.313 & -0.290 & 1 & & \\
\hline Education & & & 0.327 & 0.445 & 0.416 & 0.748 & 0.443 & 0.571 & 0.626 & 0.408 & 1 & \\
\hline
\end{tabular}

Note: All correlation coefficients are significant at 0.01 level 


\section{Results and Discussion}

Statistical analysis of SEM was carried out using LISREL 8.2 software and Maximum Likelihood Estimation (MLE) as estimation method. The following tests were deployed: Chi-square, Normed chi-square. Goodness of Fit Index (GF1), Normed Fit Index (NFI), Comparative Fit Index (CFI) and Root Mean Square Error of Approximation (RMSEA).

The application of the SEM procedure on the proposed sample led the indices for Goodness of Fit near or over their admissibility limits, GF $1=0.88$, AGFI $=0.77$, NFI $=0.89$, $\mathrm{CFI}=0.92$ and $\mathrm{RMSEA}=0.080$.

The present research was motivated by the increased interest in comprehending user behavior towards information technologies. Being aware of the fact that the nature of information technologies has changed significantly, we maintained the need to focus our attention on the experiences that contribute to the faster adoption of IT in the hospitality industry.

The Personal Characteristics are positively correlated (0.24) and statistically significant with Perceived IT Beliefs confirming the hypothesis $\mathrm{H} 1$

The self-confidence of the employees of a hotel, reinforced by the perception of employees regarding their Self-Efficacy, following the impact of their Personal Characteristics, may be affect their Attitude.

However, the findings show that the Self-Efficacy correlate (0.31), but not statistically significant, the Perceived IT Beliefs, differently from previous works, such as Conger J, and Kanungo R. (1988); Gist M. and Mitchell T.(1992); Stajcovic A. and Luthans F. (1998).

In any case Hypothesis $\mathrm{H} 2$ is not verified and only Personal Characteristics positively interrelate with Perceived IT Beliefs, confirming the Hypothesis $\mathrm{H} 1$ and supporting the findings of previous study as Igbaria M. and Ivari J. (1990), Guimares T., Yoon Y. and Clevenson A.(1996), Cho V. (2006), Bai B., Law R. and Wen I. (2008) and Lee H. and Lee Y. (2006).

The correlations according also to Figure 2, between Perceived IT Beliefs and Attitude (0.41) are positive and statistically significant, thus corroborating hypothesis H3. Furthermore, the correlations between Attitude and Behavioral Intention (0.50) are positive and statistically significant, thus corroborating $\mathrm{H} 5$, which is also confirmed in previous studies such as Davis F. (1993), Chau P. and Hu P. (2002), Yang H. and Yoo Y. (2004), Han H., Hsu T. and Lee S. (2009), Lam T. et al. (2007).

Even the Task-technology fit are positively and statistical significant correlated with the Attitude, influencing her positively, which confirms the hypothesis H4.

Subjective Norm have a positive impact (0.49) on Behavioral Intention, as is demonstrated by the statistically significant correlations between them and thus verifying hypotheses H6.

In the present study, on the contrary, of the sample employed, the external variables Self-Efficacy and Personal Characteristics affect only Perceived IT Beliefs,
Task-Technology has an impact on Attitude and Subjective Norm only on Behavioral Intention.

\section{Last Notes}

The proposed coefficients (PC) - including the views regarding behaviour towards IT use, which constitutes the result of the former - as well as the individual characteristics of personal skill regarding the ease in using a computer, strongly support, just like the previous results, the relationships they presuppose, as well as the direct relation between IT and the intent to use them.

Findings based on correlations between all variables may possibly lead to hazy results, due to the interaction between the various variables and because of this the test for discriminant validity is carried out by testing which of the interrelated variable pairs are significantly different than one, Gefen D., Straub D. and Boudreau S. (2000).

The aim of the present research was to determine the fundamental decisive factors influencing the intent to accept the use of PC and to render explicit the way in which they affect the dependent variable. For this purpose, consumer behaviour as seen in the literature was reshaped and adapted so as to be incorporated in the previous research and so that, further on, its use can be theoreticized in a PC model.

The empirical data support some of our assumptions, but not all of them.

The combination/ fusion of two factors, the factor of the discrete usefulness and the factor of usability, and their alternative substitution by one and only factor, that of discretional beliefs on IT Lam T. et al. (2007), appears to be comparatively functional.

The property- variable of self-efficacy is based on the employees' prior contact or lived experience with various computer applications and in the existence of a high level of information regarding the new technologies. Nevertheless, this kind of knowledge is not very widespread in persons coming from the local province, whereas this particularity seems to be further accentuated by gender differentiation.

Another particularity that likely affects the statistical significance of Self-Efficacy is the strong Mediterranean character of local employees in tourist areas, which may lead them to display excessive confidence in regards to their knowledge of new technologies, even though these are not always implemented properly.

Furthermore, the fact that the majority of questionnaires were completed by employees of a young age who, due to their provenance from mostly rural areas, did not have the opportunity to receive high levels of information on new technologies, also reinforces this possibility.

These personal characteristics, which are essentially common for the majority of the tourism sector in Greece and which make up the particular developmental potential of the sector, require methodical training for their full and profitable utilization.

A traditional, generic presentation of the subject of IT and 
IT-related knowledge would not be as effective as a training targeted for an audience with the above characteristics. This should highlight in a practical way those points in the production chain where it seems most likely that there is the potential to save time, effort and cost and, consequently, to significantly improve productivity. Furthermore, in order for the trainees to acquire a complete knowledge of IT, it is very important that they receive a presentation not just of the specific phase related to their personal duties involving information technologies, but also of the phase previous to their own, and of the phase subsequent. Such an approach to training ensures that the employees will acquire complete clarity regarding the potential for them to achieve, through IT, savings in the productive process and, consequently, an improvement in productivity.

These results seem to confirm the mediating effect of 'deterministic' variables for the acceptance of IT in hotels as recorded and in a substantial part of the literature

The substitution of the variables, Perceived Usefulness and Perceived Ease of Use, by the conventional variable Perceived IT Beliefs, as proposed by Lam T. et al. (2007), works particularly effective.

Little by little, technology tends to become a critically important permanent competitive advantage for the hospitality industry. In view of the benefits it provides to the industry, the extensive use of technology appears to be inevitable.

In addition, the adoption of technology by hotels requires a differentiated approach in investigating employee acceptance of technology, due to the complex procedure affecting both the internal and external variables and their unique characteristics.

JEL Classification: M210, D23, D24, C12, C40

\section{References}

[1] Prof. Alberta Bandura, Nancy E. Adams., Arthur B. Hardy, Howells N. Gary, Tests of the Generality of Self- Efficacy Theory, Cognitive Therapy and Research, 03-1980 4:1 pp.39-66. doi: 10.1007/BF01173354

[2] Prof. Alberta Bandura, Self-Efficacy Mechanism in Human Agency, American Psychologist, 02 -1982 37:2 pp. 122-147. doi: org/10.1037/0003-066X.37.2.122

[3] Prof. Alberta Bandura, Self-Efficacy Determinants of Anticipated Fears and Calamities, Journal of Personality and Social Psychology, 08-1983 45:2, pp. 464-469. doi.org/10.1037/0022-3514.45.2.464

[4] Anol Bhattacherjee, Understanding Information Systems Continuance: An Expectation - Confirmation Model, MIS Quarterly, 09-2001 25:3, pp.351-370.

[5] Anol Bhattacherjee, G. Premkumar, Understanding Changes in Belief and Attitude Toward Information Technology Usage: A Theoretical Model and Longitudinal Test, MIS Quarterly, 06-2004 28:2, pp. 229-254.

[6] Alexander D. Stajkovic, Fred Z. Luthans, Self-Efficacy and a Word Related Performance: A Meta-Analysis, Psychological Bulletin, 01-1998 124:2, pp. 240-261.
[7] Alexandros Paraskevas, Prof. Dimitrios Buhalis, Outsourcing IT for small hotels: the opportunities and challenges of using application service providers. Cornel Hotel and Restaurant Administration Quarterly, 04-2002 pp. 27-39. doi:10.1016/S0010-8804(02)80029-5

[8] Barbara H. Wixom, Peter A. Todd, A Theoretical Integration of User Satisfaction and Technology Acceptance, Information Systems Research, 03-2005 16:1, pp. 85-102 doi 10.1287 /isre. 1050.0042

[9] Prof. Bille Bai, Prof. Rob Law, Prof. Ivan Wen. The impact of website quality on customer satisfaction and purchase intentions: Evidence from Chinese online visitors, International Journal of Hospitality Management, 2008, 27, pp. 391-402. doi: 10.1016/j.ijhm.2007.10.008

[10] Buttle Francis, Bok Bungkwon, Hotel Marketing Strategy and the theory of reasoned action, International Journal of Contemporary Hospitality, $1996 \quad 8: 3 \quad$ pp. 5-10 doi.org/10.1108/09596119610115943

[11] Prof. Cathy A. Enz, Prof. Judy A. Siguaw, Best Practices in Human Resources, Cornell Hotel and Restaurant Administration Quarterly, 2000 41: 1 February 2000, pp 48-61 doi: $10.1177 / 001088040004100123$

[12] Prof. Cathy A. Enz, What Keeps You Up at Night? Key Issues of Concern for Lodging Managers, Cornell Hotel and Restaurant Administration Quarterly, April 2001 42:38, pp 38-45. doi:10.1016/S0010-8804(01)80037-9

[13] Prof. Dale L. Goodhue, Prof. Barbara D. Klein, Prof. Salvatore T. March, User evaluations of IS as surrogates for objective performance, Information \& Management, 2000 38, pp.87-101. doi:10.1016/S0378-7206(00)00057-4

[14] Prof. Dale L. Goodhue, Prof. Ronald L. Thompson, Task-Technology Fit and Individual Performance, MIS Quarterly, June 1995, pp.213-236.

[15] Daryl Ansel, Chris Dyer, A Framework for Restaurant Information Technology, Cornell Hotel and Restaurant Administration Quarterly, 40:3 06-1999, pp.74-84 doi:10.1016/S0010-8804(99)80040-8

[16] Prof. David Corsun, Prof. Cathy Enz, Predicting Psychological Empowerment among Service Workers: The Effect of Support-Based Relationships, Human Relations, 1999 52:2, pp. 205-224. doi: 10.1177/001872679905200202

[17] Prof. David Gefen, Prof. Detmar Straub, Prof. Marie-Claude Boudreau, Structural Equation Modeling and Regression: Guidelines for Research Practice, Communication of the Association for Information Systems, August 2000, 4, pp. 2-79.

[18] Prof. Dennis A. Adams, Prof. Ryan R. Nelson, Prof. Peter A Todd, Perceived Usefulness, Ease of Use, and Usage OF Information Technology: A Replication, MIS Quarterly, 6-1992, 15:2, pp. 227- 250.

[19] Prof. Dimitris Buhalis, Prof. Hilary Main, Information technology in peripheral small and medium hospitality enterprises: strategic analysis and critical factors, International Journal of Contemporary Hospitality Management, 1998 10:5, pp. 198-202. doi.org/10.1108/09596119810227811

[20] Prof. Dimitris Buhalis, Ourania Deimezi, Information Technology Penetration and e-commerce developments in Greece with a focus on small to medium-sized enterprises, Electronic markets, 2003 13:4, doi: $10.1080 / 1019678032000135563$ 
[21] Prof. Dimitris Buhalis, Rob Law, Progress in information technology and tourism management : 20 on and 10 after the internet - the state of e-tourism research, Tourism management, 2008, 29, pp.609-623 doi : 10.1016/j.tourman.2008.01.005

[22] Prof. Dimitris Buhalis, Daniel Leung, Rob Law, eTourism: Critical Information and Communication Technologies for Tourism Destinations, Destination Marketing and Management, 2011 pp. $205-224$

[23] Prof. Dimitris Buhalis, Konstantina Kaldis, eEnabled Internet Distribution for Small and Medium Sized Hotels: The Case of Hospitality SMEs in Athens, Tourism Recreation Research, 2008 33:1

[24] Prof. Echo Huang, Meng H. Chuang, Extending the theory of planned behaviour as a model to explain post-merger employee behaviour of IS use, Computers in Human Behaviour, $2007 \quad 23, \quad$ pp. 240- 257. doi:10.1016/j.chb.2004.10.010

[25] Prof. Elena Karahanna, Prof. Detmar W. Straub, The psychological origins of perceived usefulness and ease-of-use, Information \& Management, 1999 35, pp.237-250. doi:10.1016/S0378-7206(98)00096-2

[26] Prof. Elena Karahanna, Prof. Detmar W. Straub, Norman Chervany, Information Technology Adoption Across Time: A Cross-Sectional Comparison of Pre-Adoption and Post-Adoption Beliefs, MIS Quarterly, June 1999, pp.183-213.

[27] Elizabeth J. Davidson, Technology Frames and Framing: A Socio-cognitive Investigation of Requirements Determination, MIS Quarterly, 12-2002 26:4, pp.329-358.

[28] Everett M. Rogers, Diffusion of Innovations, $3^{\text {th }}$ edition, Macmillan, New York, 1983

[29] Prof. Fred D. Davis, Perceived Usefulness, Ease of Use, and User Acceptance of Information technology, MIS Quarterly, September 1989, 13:3, pp. 319-340.

[30] Prof. Fred D. Davis, Richard P. Bagozzi, Paul R. Washaw, User Acceptance of Computer Technology: A Comparison of two Theoretical Models, Management Science, August 1989 35:8, pp. 982-1003. doi.org/10.1287/mnsc.35.8.982

[31] Prof. Fred D. Davis, User acceptance of information technology; system characteristics, user and behavioral impacts, International Journal of Man-Machine Studies, 1993 38, pp. 475-487. doi:10.1006/imms.1993.1022

[32] Prof. Fred D. Davis, Viswanath Venkatesh, Measuring User Acceptance of Emerging Information Technologies: An Assessment of Possible Method Biases, Proceedings of the 28th Annual Hawaii International Conference on System Sciences, IEEE, 1995 pp.729-736. doi: 10.1109/HICSS.1995.375675

[33] Prof. Fred D. Davis, Viswanath Venkatesh, A critical assessment of potential measurement biases in the technology acceptance model: three experiments, International Journal of Human - Computer Studies, 1996 45, pp.19-45. doi:10.1006/ijhc. 1996.0040

[34] G. Maxwell, M. McDougall and S. Blair, Managing Diversity in the hotel sector; The Emergence of a service quality opportunity, Managing Service Quality, 11 01-2000, pp. 367-373. doi:10.1108/09604520010351176
[35] Gary C. Moore and Izak Benbasat, Development of an Instrument to Measure the Perceptions of Adopting An Information Technology Innovation, Information Systems Research, 1991 2:3 , pp.192-22.

[36] George M. Marakas, Mun Y. Yi and Richard D. Johnson, The Multilevel and Multifaceted Character of Computer Self-Efficacy: Toward Clarification of the Construct and an Integrative Framework for Research, Information Systems Research, 061998 9:2, pp.126-163. doi: 10.1287/isre.9.2.126

[37] Guy Pare and Joyce Elam, Discretionary use of personal computers by knowledge testing of a social psychology theoretical model, Behavior \& Information Technology, 1995 14:4, pp. 214-228. doi: 10.1080/01449299508914635

[38] Hae Y. Lee, Woo G. Kim, Yong-Ki Lee, Testing the determinants of Computerized Reservation System User's Intention to Use via a Structural Equation Model, Journal of Hospitality \& Tourism Research, 2006 30: 2, 246-266. doi: $10.1177 / 1096348005285087$

[39] Hayashi Albert, Prof. Chen Charlie, Prof. Ryan Terry, Prof. Wu Jiinpo, The Role of Social Presence and Moderating Role of Computer Self Efficacy in Predicting the Continuance Usage of E-Learning Systems, Journal of Information Systems Education, 2001 15:2, pp.139-155.

[40] Prof. Hee-dong Yang, Prof. Youngjin Yoo, It's all about attitude revisiting the technology acceptance Model, Decision Support Systems, $2004 \quad 38, \quad$ pp.19-31, doi:10.1016/S0167-9236(03)00062-9

[41] Heesup Han, Li-Tzang Hsu, Jin-Soo Lee, Empirical investigation of the roles of attitudes toward green behaviours, overall image, gender, and age in hotel customers' eco-friendly decision-making process, International journal of Hospitality Management, $2009 \quad 28, \quad$ pp. $519-\quad 528$. doi:10.1016/j.ijhm.2009.02.004

[42] Hilary Main, Information technology and the independent hotel-failing to make the Connection, International Journal of Contemporary Hospitality Management, 1995 7:6, pp.30-32. doi:10.1108/09596119510095370

[43] Howard J. Klein., Raymond A. Noe, Chongwei Wang, Motivation to learn and course outcomes: The impact of delivery mode, learning goal, orientation, and perceived barriers and enablers, Personnel Psychology, 2006 59, pp.665-702. doi: 10.1111/j.1744-6570.2006.00050.x

[44] Hyang J. Huh, Taegoo Kim, Rob Law, A comparison of competing theoretical models for Understanding acceptance behaviour of information systems in upscale hotels, International Journal of Hospitality Management, 2009 28, pp. 121-134. doi:10.1016/j.ijhm.2008.06.004

[45] Hu P. Hwa-Jen Paul, Clark H. K. Theodore, Ma B. Will, Examining Technology Acceptance, Information \& Management, $2003 \quad 41 \quad$ pp. 227-241. doi:10.1016/S0378-7206(03)00050-8

[46] Ian Buick, Information technology in small Scottish hotels: is it working?, International Journal of Contemporary Hospitality $\begin{array}{llll}\text { Management, } & 2003 & 15: 4 & \text { pp. 243-247. }\end{array}$ doi:10.1108/09596110310475711

[47] Prof. Icek Ajzen, The Theory of Planned Behavior, Organizational, Behavior and Human Decision Processes, 50, 1991 pp.179-211. doi:10.1016/0749-5978(91)90020-T 
[48] Prof. Icek Ajzen, Thomas J. Madden, Prediction of Goal-Directed Behavior: Attitudes, Intentions and Perceived Behavioral Control, Journal of Experimental Social Psychology, August 5-1986, 22:2, pp. 453-474. doi:10.1016/0022-1031(86)90045-4

[49] Prof. Jay A. Conger, Prof. Rabindra N. Kanungo, The Empowerment Process: Integrating Theory and Practice, Academy of Management Review, 06071988 13:3 pp. 471- 482 doi:10.5465/AMR.1988.4306983

[50] Jennifer Xiaoqiu Ma, Prof. Dimitrios Buhalis, Prof. Haiyan Song, ICTs and Internet adoption in China's tourism industry, International Journal of Information Management 12-2003 23:6 451-467, doi:10.1016/j.ijinfomgt.2003.09.002

[51] Prof. Jeff Jiang, Prof. Mark E Havitz, Prof. Robert M. O'Brien, Validating the International Role Scale, Annals of Tourism Research, $2000 \quad 27: \quad 4, \quad$ pp. $904-981$. doi:10.1016/S0160-7383(99)00111-5

[52] Ji-Won Moon and Young-Gul Kim Extending the TAM for a World-Wide-Web context, Information \& Management, 2001 38, pp. 217-230. doi:10.1016/S0378-7206(00)00061-6

[53] John Bowen, A market driven approach to business development and service improvement in the hospitality industry, International Journal of Contemporary Hospitality, 1997, 9:7 pp. 344-345. doi.org/10.1108/09596119710191001

[54] Joost W. M. Verhoeven, Thomas J. L. van Rompay, Ad T. H. Puyn., The price facade: Symbolic and behavioural price cues in service environments, International Journal of Hospitality Management, $2009 \quad 28, \quad$ pp.604-611. doi:10.1016/j.ijhm.2009.03.013

[55] Judy A. Siguaw, Cathy A. Enz, karthik Namasivayam, Adoption Information Technology in U.S. Hotels: Strategically Driven Objectives, Journal of Travel Research, 200039 pp.192-201. doi:10.1177/004728750003900209

[56] Karen Huchting, Andrie Lac, Joseph W. LaBrie, An application of the Theory of Planned Behavior to sorority alcohol consumption, Addictive Behaviours, 2008 33, pp. 538-551. doi:10.1016/j.addbeh.2007.11.002

[57] Kieran Mathieson, Predicting User Intentions: Comparing the Technology Acceptance Model with the Theory of planned Behavior, Information Systems Research, 1991 2:3 , pp.173-191. doi:10.1287/isre.2.3.173

[58] Prof. Magid Igbaria, End-User Computing Effectiveness: A Structural Equation Model, OMEGA; International Journal of Management Science, 1990 18:6, pp.637-652. doi:10.1016/0305-0483(90)90055-E

[59] Prof. Magid Igbaria, Juhani Livari, The Effects of Self-Efficacy on Computer Usage, OMEGA; International Journal of Management Science, 1995 23:6, pp. 587- 605. doi:10.1016/0305-0483(95)00035-6

[60] Prof. Magid Igbaria, Juhani Livari, Hazem Maragahh, User Acceptance of Computer Technology: A Comparison of Two Theoretical Models, Management Sciences, 1995 35:8, pp.9821003. doi.org/10.1287/mnsc.35.8.982

[61] Prof. Marilyn E. Gist, Prof. Terence R. Mitchell, Self-Efficacy: A Theoretical Analysis of Its Determinants and Malleability, Academy of Management Review, 041992 17:2 pp.183- 211. doi:10.5465/AMR.1992.4279530
[62] Mark Conner, Sara F.L Kirk., Janet E. Cade, Jennifer H. Barrett, Why do women use dietary supplements? The use of the theory of planned behaviour to explore beliefs about their use, Social Science and Medicine, 2001 52, pp.621-633. doi:10.1016/S0277-9536(00)00165-9

[63] Mark T. Dishaw, Prof. Diane M. Strong, Extending the technology acceptance model with task-technology fit constructs, Information \& Management, 1999 36, pp. 9-21. doi:10.1016/S0378-7206(98)00101-3

[64] Martin Fishbein, Prof. Icek Ajzen, Bilief, Attitude, intention and behaviour: an introduction to theory and research, Reading, MA : Addition Wesley, 1975

[65] Michelle L. Heine, Varun Grover, Manoj K. Malhotra, The relationship between technology and performance: a meta-analysis of technology models, International Journal of Management Sciences, $01 \quad 29-2003$ pp.189-204. doi:10.1016/S0305-0483(03)00026-4

[66] Michael G. Morris amd Jason M. Turner, Assessing users' subjective quality of experience with the world wide web: an exploratory examination of temporal changes in technology acceptance, International Journal of Human-Computer Studies, 200154 , pp.877-901. doi:10.1006/ijhc.2001.0460

[67] Prof. Mun Y. Yi, Joyce D. Jackson, Prof. Jae S. Park, Prof. Janice C. Probst, Understanding Information Technology acceptance by individual professionals: Toward an integrative view, Information \& Management, 2006 43, pp. 350-363. doi:10.1016/j.im.2005.08.006

[68] Prof. Murugan Anandarajan, Magid Igbaria, Prof. Uzoamaka P. Anakwe, IT acceptance in a less-developed country: a motivational factor perspective, International Journal of Information Management, 2002, 22 pp. 47-65. doi:10.1016/S0268-4012(01)00040-8

[69] Prof. Nabil N. Kamel, Prof. Robert M. Davison, Applying CSCW technology to overcome traditional barriers in group interactions, Information \& Management, 1998 34, pp. 209-219. doi:10.1016/S0378-7206(98)00056-1

[70] Neil C. Ramiller, Perceived compatibility of Information Technology innovation among Secondary adopters: Toward a reassessment, Journal of Engineering and Technology Management, $1994 \quad 11, \quad$ pp. $1-23$. doi:10.1016/0923-4748(94)90022-1

[71] Nunnally J. C. (1978), "Nunnally on Reliability", http://core.ecu.edu/psyc/wuenschk/ stathelp/Reliab-Nunnally.doc

[72] Prof. Patrick Y. K. Chau, An empirical investigation on factors affecting the acceptance of CASE by systems developers, Information \& Management, 199630 pp. 269-280. doi:10.1016/S0378-7206(96)01074-9

[73] Prof. Patrick Y. K. Chau, Prof. Paul J.H. Hu, Information Technology Acceptance by Individual Professionals: A Model Comparison Approach, Decision Sciences, Fall 2001 32:4, pp.699-719. doi: 10.1111/j.1540-5915.2001.tb00978.x

[74] Prof. Patrick Y. K. Chau, Prof. Paul J.H. Hu, Investigating healthcare professionals' decisions to accept telemedicine technology: an empirical test of competing theories, Information \& management, 2002 39, pp.297-311. doi:10.1016/S0378-7206(01)00098-2 
[75] Prof. Patrick Y. K. Chau, Prof. Paul J.H. Hu, Examining a Model of Information Technology Acceptance by Individual Professionals: An Exploratory Study, Journal of Management Information Systems, spring 2002 b 18:4, pp. 191-229.

[76] Prof. Paul J. Hu, Prof. Patric Y.K. Chau, Prof. Olivia L.R. Sheng, Prof. Kam Tam, Examining the Technology Acceptance Model Using Physician Acceptance of Telemedicine Technology, Journal of Management Information Systems, Fall 1999 16:2, pp. 91-112.

[77] Prof. Paul J.H. Hu, Prof. Theodore H.K. Clark, Will W. Ma, Examining technology acceptance by school teachers: a longitudinal study, Information \& Management, 2003 41, pp. 227-241. doi:10.1016/S0378-7206(03)00050-8

[78] Paul Pavlou and Chai Lin, What drives electronic commerce across cultures? A cross-cultural empirical investigation of the theory of planned behavior, Journal of Electronic Commerce Research, 2002 3:4, pp. 240-253.

[79] Paul Pavlou and Mendel Fygenson, Understanding and Predicting Electronic Commerce Adoption: An Extension of the Theory of Planned Behavior, MIS Quarterly, 2006 3:1, pp. 115-143.

[80] Petre E. D. Love, Zahir Irani, Craig Standing, Chad Lin, Janice M. Burn, The enigma of evaluation: benefits, costs and risks of IT in Australian small-medium-sized enterprises, Information \& Management, 01-2005 42 pp. 947-964. doi:10.1016/j.im.2004.10.004

[81] Peter Roberts and Ron Henderson, Information Technology acceptance in a sample of Government employees: a test of the technology acceptance model, Interacting with Computers, 2000 12, pp.427-443, doi:10.1016/S0953-5438(98)00068-X

[82] Prodromos D Chatzoglou, Lazaros Sarigiannidis, Eftichia Vraimaki, Anastasios Diamantidis, Investigating Greek employees' intention to use web-based training, Computers \& $\begin{array}{lllll}\text { Education, } & 2009 & 53 & \text { pp. } & 877-889 \text {. }\end{array}$ doi:10.1016/j.compedu.2009.05.007

[83] Prof. Ritu Agarwal, Prof. Jayesh Prasad, The Role of Innovation Characteristics and Perceived Voluntariness in the Acceptance of Information Technologies, Decision Sciences, summer 1997, $28 \quad: \quad 3, \quad$ pp. 557-582. doi: 10.1111/j.1540-5915.1997.tb01322.x

[84] Prof. Ritu Agarwal, Prof. Jayesh Prasad, Are Individual Differences Germane to the Acceptance of New Information Technologies?, Decision Sciences, spring-1999, 30 : 2, pp. 361-391. doi: 10.1111/j.1540-5915.1999.tb01614.x

[85] Prof. Ritu Agarwal, Prof. Elena Karahanna, Time flies when you're having fun: Cognitive Absorption and Beliefs about Information Technology Usage, MIS Quarterly, 2000, 24:4 pp. 665-694.

[86] Prof. Ritu Agarwal, Prof. V Sambamurthy., Prof. Ralf M. Stair, Research Report: The Evolving Relationship Between General and Specific Computer Self-Efficacy-An Empirical Assessment, Information Systems Research, 11:4, December 2000, pp. 418- 430. doi.org/10.1287/isre.11.4.418.11876

[87] Prof. Richard P Bagozzi., Prof. Youjay Yi, On the Evaluation of Structural Equation Models, Journal of the Academy of Marketig Sciences, spring 1988, 16:1, pp. 74-94. doi: 10.1007/BF02723327
[88] Prof. Rita Kukafka, Prof. Stephen B. Johnson, Allison Linfante, John P. Allegrante, Grounding a new information technology implementation framework in behavioral science: a systematic analysis on the literature on IT use, Journal of Biomedical Informatics, 06-2003 36:30, pp. 218-227. doi:10.1016/j.jbi.2003.09.002

[89] Rob Law, Rosanna Leung, Dimitrios Buhalis, Information Technology Applications in Hospitality and Tourism: A Review of Publications from 2005 to 2007, Journal of Travel \& Tourism Marketing, 200926 599-623, doi: $10.1080 / 10548400903163160$

[90] Ron Henderson and Megan Divett, Perceived usefulness, ease of use and electronic supermarket use, International Journal of Human Computer Studies, 2003 59:3, pp. 383-395. doi:10.1016/S1071-5819(03)00079-X

[91] Prof. Ronald L. Thomson, Prof. Christopher A. Higgins, Prof. Jane M. Howell, Influence of Experience on Personal Computer Utilization: Testing a Conceptual Model, Journal of Management Information Systems, 06-1994 11:1, pp. 167-187

[92] Saade Raafat and Bouchaib Bahli, The impact of cognitive absorption on perceived usefulness and perceived ease of use in on-line learning: an extension of the technology acceptance model, Information \& Managemet, 2005 42, pp. 317-327 doi:10.1016/j.im.2003.12.013

[93] Prof. Sandra Watson, Conceptual model for analysing management development in the hospitality industry: A UK perspective, International Journal of Hospitality Management, 2008 27:3, pp. 414-425. doi:10.1016/j.ijhm.2008.01.002

[94] Satta Alessio, Tourism in the Mediterranean: Processes and Impacts on Coastal Environment, 2004 http://www.academia.edu/643353/, pp.14.

[95] Sharon Kemp, Dr. Larry Dwyer, An examination of organizational culture-the Regent Hotel Sydney, International Journal of Hospitality Management, 2001 20, pp.77-93. doi:10.1016/S0278-4319(00)00045-1

[96] Prof. Shin Y. Hung, Chia M. Chang, User acceptance OG WAP services: test of competing theories, Computer Standards \& Interfaces, 2005 27, pp.359-370. doi:10.1016/j.csi.2004.10.004

[97] Prof. Shirley Taylor, Prof. Peter Todd, Assessing IT Usage: The Role of Prior Experience, MIS Quarterly, 12 -1995 19:4, pp. 561-570. doi: $10.2307 / 249633$

[98] Sun Heshan and Ping Zhang, The role of moderating factors in user technology acceptance, International journal of Human-Computer Studies, 2006 64:2, pp. 53-78. doi:10.1016/j.ijhes.2005.04.013

[99] Sunny Ham, Woody G. Kim, Hazel W. Forthsythe, Restaurant Employees' Technology Use Intention: Validating Technology Acceptance Model with External Factors, Journal of Hospitality Marketing \&Management, 2008 17:1, pp. 78-98. doi:10.1080/10507050801978422

[100] Prof. Tor Guimaraes, Prof. Yougohe Yoon, Aaron Clevenson, Factors important to expert systems success A field test, Information \& Management 1996 30, pp.119-130. doi:10.1016/0378-7206(95)00042-9

[101] Terry Lam, Vincent Cho, Hailin Qu, A study of Hotel Employee Behavioural Intentions Towards Adoption of Information Technology, Hospitality Management, 2007 26, pp.49-65. doi:10.1016/j.ijhm.2005.09.002 
[102] Tung Ching Lin and Chien-Chih Huang, Understanding knowledge management system usage antecedents: An integration of social cognitive theory and task technology fit, Information \& Management, 2008 45, pp. 410-417. doi:10.1016/j.im.2008.06.004

[103] Thomas Zwick, Employee resistance against innovations, International Journal of Manpower, 2002 23:6, pp. 542-552. doi: $10.1108 / 0.437720210446397$

[104] Valeria Minghetti, Prof. Dimitrios Buhalis, Digital Divide in Tourism, Journal of Travel Research, , 10 20-2009, pp 1-15, doi: $10.1177 / 0047287509346843$

[105] Prof. Vincent Cho, A study of the roles of trusts and risks in information-oriented online legal services using an integrated model, Information \& Management, February 14-2006, pp.502-520. doi:10.1016/j.im.2005.12.002

[106] Prof. Viswanath Venkatesh, Prof. Fred D. Davis, A Theoretical Model of the Technology Acceptance Model: Four Longitudinal Field Studies, Management Science, 2000 46:2 pp.186 - 204.
[107] Prof. Viswanath Venkatesh, Prof. Michael G. Morris, Prof. Gordon B. Davis, Prof. Fred D. Davis, User acceptance of Information technology: Toward a unified view, MIS Quarterly, 09-2003 27:3, pp. 425-478.

[108] Weiyin Hong, Prof. James Y.L. Thong, Wai-.Man Wong, Prof. Kar-Yan Tam, Determinants of User Acceptance of Digital Libraries: An Empirical Examination of Individual Differences and System Characteristics, Journal of Management Information Systems, winter 2001-2002, 18:3, pp.97-124.

[109] William Lewis, Ritu Agarwal and V. Sambamurthy, Sources of Influence on Beliefs about Information Technology Use; An Empirical Study Of Knowledge Workers, MIS Quarterly, 12-2003 27:4, pp.657-678.

[110] Youcheng Wang, William Qualls, Towards a theoretical model of technology adoption in hospitality organizations, Hospitality Management, 2007 26, pp. 560-573. doi: 10:1016/j.ijhm.2006.03.008 